\title{
Correction to: Digital Transformation for a Sustainable Society in the 21st Century
}

Ilias O. Pappas (D), Patrick Mikalef(D), Yogesh K. Dwivedi (D), Letizia Jaccheri (D), John Krogstie, and Matti Mäntymäki (D)

\section{Correction to:}

I. O. Pappas et al. (Eds.): Digital Transformation for a Sustainable Society in the 21st Century, LNCS 11701, https://doi.org/10.1007/978-3-030-29374-1

The original versions of the chapters "The Role of Big Data in Addressing Societal Challenges: A Systematic Mapping Study" and "Organizational Culture Challenges of Adopting Big Data: A Systematic Literature Review" have been revised. The Marie Sklodowska-Curie Grant Agreements No. has been corrected from 751550 to 751510.

The updated version of these chapters can be found at https://doi.org/10.1007/978-3-030-29374-1_13 https://doi.org/10.1007/978-3-030-29374-1_14 